Louisiana State University

LSU Digital Commons

Faculty Publications

Department of Biological Sciences

$9-15-2012$

\title{
Hypothalamus-pituitary-adrenal axis activity and the subsequent response to chronic stress differ depending upon life history stage
}

Christine R. Lattin

Tufts University

Carolyn M. Bauer

Tufts University

Robert de Bruijn

Tufts University

L. Michael Romero

Tufts University

Follow this and additional works at: https://digitalcommons.Isu.edu/biosci_pubs

\section{Recommended Citation}

Lattin, C., Bauer, C., de Bruijn, R., \& Michael Romero, L. (2012). Hypothalamus-pituitary-adrenal axis activity and the subsequent response to chronic stress differ depending upon life history stage. General and Comparative Endocrinology, 178 (3), 494-501. https://doi.org/10.1016/j.ygcen.2012.07.013

This Article is brought to you for free and open access by the Department of Biological Sciences at LSU Digital Commons. It has been accepted for inclusion in Faculty Publications by an authorized administrator of LSU Digital Commons. For more information, please contact ir@lsu.edu. 


\title{
Hypothalamus-pituitary-adrenal axis activity and the subsequent response to chronic stress differ depending upon life history stage
}

\author{
Christine R. Lattin*, Carolyn M. Bauer, Robert de Bruijn, L. Michael Romero \\ Department of Biology, Tufts University, Medford, MA 02155, United States
}

\section{A R T I C L E I N F O}

\section{Article history}

Received 8 February 2012

Revised 3 July 2012

Accepted 13 July 2012

Available online 25 July 2012

\section{Keywords}

Corticosterone

Acute stress

Negative feedback

Adrenal sensitivity

House sparrow

Captivity

\begin{abstract}
A B S T R A C T
The hypothalamus-pituitary-adrenal (HPA) axis is modulated seasonally in many species, and chronic stress can alter HPA functioning. However, it is not known how these two factors interact - are there particular life history stages when animals are more or less vulnerable to chronic stress? We captured wild house sparrows (Passer domesticus) in Massachusetts during six different life history stages: early and late winter, pre-laying, breeding, late breeding, and molt. At each time point, we tested HPA function by measuring baseline and stress-induced corticosterone (CORT), negative feedback in response to an injection of dexamethasone, and maximum adrenal response through an injection of adrenocorticotropic hormone. We then brought birds into captivity as a model for chronic stress, and repeated the four tests 5 days later. At capture, all HPA variables varied seasonally. Birds showed increased negative feedback during breeding and late winter compared to pre-laying. Furthermore, birds during the late breeding period had down-regulated their HPA axis, perhaps in preparation for molt. After 5 days of captivity, house sparrows lost $\sim 11 \%$ of initial body mass, although birds lost more weight during molt and early winter. Overall, captive sparrows showed elevated baseline CORT and increased negative feedback, although negative feedback did not show a significant increase during any individual life history stage. During most of the year, adrenal sensitivity was unaffected by captivity. However, during late breeding and molt, adrenal sensitivity increased during captivity. Taken together, these data provide further support that HPA function naturally varies throughout the year, with the interesting consequence that molting birds may potentially be more vulnerable to a chronic stressor such as captivity.
\end{abstract}

(c) 2012 Elsevier Inc. All rights reserved.

\section{Introduction}

The hypothalamus-pituitary-adrenal (HPA) axis is essential in helping wild animals cope with environmental challenges through the secretion of the glucocorticoid hormones corticosterone or cortisol (CORT) [51]. HPA activity is modulated seasonally in many species, with patterns such as increased baseline and stress-induced CORT during breeding occurring across many different vertebrate taxa (for review, see [42]). Presumably, these changes to the HPA axis help animals cope with the predictable challenges associated with different life history stages [32,45], e.g. in molting birds, low CORT may be necessary for the growth of high-quality feathers $[15,48]$.

Although changes in CORT associated with different life history stages may be adaptive, chronic or prolonged exposure to stressors may also alter the HPA axis in non-adaptive ways [63]. This involves physiological changes that persist longer than the transitory rise in CORT due to an acute stressor, such as long-term changes in baseline and stress-induced hormone secretion $[12,40]$, negative feedback [50] and receptor expression [19]. One

\footnotetext{
* Corresponding author.

E-mail address: christine.lattin@tufts.edu (C.R. Lattin).
}

such prolonged stressor is the transference of wild animals into captivity. Captivity has been shown to change the HPA axis in ways consistent with a chronic stressor; for example, alterations in baseline CORT, stress-induced CORT and negative feedback that persist for several days $[4,18]$. Persistent activation of the HPA axis due to chronic stress can cause immune and reproductive suppression, disruptions to metabolism and other pathologies [5,16,33]. However, it is not known how seasonal changes in the HPA axis may affect this: are there particular life history stages when animals are more or less vulnerable to prolonged chronic stressors such as captivity?

To investigate this question, it might be useful to look across a wider range of life history stages - few studies have examined seasonal differences in HPA function beyond distinguishing between breeding and nonbreeding [42]. However, breeding and nonbreeding are not homogeneous life-history stages. For example, wild animals potentially need to regulate energy use very differently in late winter, when they are coming into breeding condition and undergoing rapid gonadal recrudescence, then they do in early winter [59].

Also, although many studies measure both baseline CORT (which regulates metabolism and activity levels) and stressinduced CORT (which helps animals cope with stressors) [27], 
negative feedback is another feature of HPA function that has recently attracted attention $[20,53]$. Although there is little information on how, or even whether, negative feedback efficacy might change seasonally, negative feedback appears to be a critical aspect of HPA function. For example, reduced efficacy of negative feedback was the only difference in the HPA profiles between Galapagos marine iguanas that survived an El Niño-induced famine and those that died [49]. Similarly, little is known about whether adrenal capacity changes seasonally. If it does, it would provide a physiological mechanism to explain previous data indicating that adrenal mass varies seasonally $[1,56]$. These measures can provide important insights into the capacity and feedback cycles of the HPA axis.

In this study, we captured wild house sparrows (Passer domesticus) at six different ecologically-relevant time points. We caught birds during the early winter and late winter with the expectation that sparrows in late winter might regulate their HPA axis differently than those in early winter because of the demands of rapid gonadal recrudescence, which begins after the winter solstice [2]. We further caught birds during pre-laying, breeding, and late breeding, hypothesizing that the HPA axis might be more sensitive before egg-laying if CORT is a hormonal mechanism through which supplemental cues (like food availability and weather) help time the onset of reproduction [60,61], whereas during breeding increased HPA function might relate to increased metabolic demand as seen in a variety of vertebrate taxa [42]. Finally, we captured birds during molt, a life history stage where birds typically dramatically down-regulate HPA function [42].

At each time point, we tested HPA function at capture. To test HPA function, we measured baseline and stress-induced CORT, negative feedback, and adrenal sensitivity. We predicted that pre-captivity changes in HPA function at different times of year would be directly related to changing metabolic needs, frequency of stressors, and, during molt, the need to downregulate HPA function to grow high-quality feathers $[32,45]$. We then repeated the testing of HPA function after five days of captivity in a laboratory setting to determine whether the chronic stress caused by captivity would interact with life history stage in complex ways. We predicted that birds would show different responses to captivity based on life-history stage and on initial HPA function.

\section{Methods}

\subsection{Study subjects}

From December 2010 to December 2011, we caught wild house sparrows at six times of year corresponding to important life history stages in New England. We caught birds during early winter (11-15 December 2010, $n=9$ and 8 December 2011, $n=8$ ), late winter (1-14 February 2011, $n=8$ ), and during three different periods related to breeding: pre-laying, (31 March-7 April 2011, $n=8$ ), breeding (23-24 May 2011, $n=8$ ), and late breeding (12-22 July $2011, n=8)$. We also caught birds during molt (9-12 September 2011, $n=9$ ); all of these birds were molting primary feathers (P3-P9). During each life history stage, we caught and sampled at least four males and four females to control for sex-specific effects in HPA function.

Plasma concentrations of CORT can change within different breeding sub-stages in house sparrows [23]. To better define reproductive status, we collected gonads from all individuals following the 5 days of the experiment. We also collected gonads from an additional set of birds ( $n=6$ males and 6 females per life history stage) caught at the same locations and times, but sacrificed $36 \mathrm{~h}$ after capture and used for a different study. Gonadal mass was measured to the nearest $10 \mathrm{mg}$ as total mass of both testes in the case of males, or of the entire ovary in the case of females.
Additionally, we collected information on the development of beak color (in males) and brood patches (in females). We photographed all males using a digital camera (Canon PowerShot SD 1000, Lake Success, NY) and had two independent observers score beak color using an arbitrary scale of $1-4$, where $1=$ uniform light yellow or horn color and $4=$ jet black [22]. Scoring was blind to time of year, and scores were averaged across the two observers. Upon capture, we noted both the extent of defeathering and color of brood patches in females.

Sparrows were caught at bird feeders in Medford and Somerville MA using mist nets and Potter traps and subjected to an HPA function test (see below). Because time of day can affect plasma CORT concentrations $[7,39,47]$, in all cases samples were taken at least one hour after sunrise until early afternoon ( $\sim 8 \mathrm{am}-2 \mathrm{pm})$. Laboratory studies show that baseline CORT in captive house sparrows is uniform throughout this period [39]; furthermore, using regression analysis we found no relationship between time of capture and plasma CORT concentrations for any life history stage (data not shown), so we did not include it in further analyses.

We kept birds in captivity for five full days before re-testing HPA function. Birds were housed in pairs under photoperiod conditions corresponding to their capture date and given ad libitum water, grit and mixed seed. A previous study examining HPA axis changes with captivity in chukar (Alectoris chukar) found the greatest changes to HPA function 3-6 days after captivity [18]. We chose five days of captivity because it fell in the late part of this range, and was the only time point where changes in negative feedback were observed in this earlier study. After five days of captivity, birds were subjected to another HPA function test and euthanized. Gonads were examined and weighed to validate breeding stage. HPA function tests resulted in $\sim 260$ ul total blood drawn, below the $1 \%$ of body weight/ 2 weeks guideline for house sparrows (which typically weigh $27-29 \mathrm{~g}$ ). All procedures involving birds were performed according to AALAC guidelines and were approved by the Tufts University Institutional Animal Care and Use Committee.

\subsection{Blood sampling}

All blood samples were collected from the alar vein using heparinized capillary tubes. Birds were offered a $50 \% \mathrm{w} / \mathrm{v}$ sucrose solution in a dropper bottle following the HPA function test. Blood samples were stored on ice until centrifugation up to $8 \mathrm{~h}$ later. After centrifugation, plasma was removed and stored at $-20^{\circ} \mathrm{C}$.

\subsection{Dexamethasone validation experiment}

Negative feedback can be tested by determining how well the synthetic glucocorticoid dexamethasone (DEX) shuts down endogenous CORT secretion. Because we wanted to ensure that we were waiting long enough to see the largest possible response to DEX, we performed a validation experiment examining initial acute CORT and response to DEX (Vedco, St. Joseph, MO) at different time periods after injection. House sparrows were caught in Potter traps and immediately placed in cloth bags for $30 \mathrm{~min}$. A stress-induced blood sample ( $\sim 30 \mathrm{ul}$ ) was taken and $1 \mathrm{mg} / \mathrm{kg}$ body weight dose of DEX $(n=3)$ or lactated Ringer's solution $(n=3)$ injected intramuscularly. This dose of DEX has been shown to be effective in birds [18]. Subsequent blood samples of $\sim 40$ ul were taken at 30,60 and 90 min post-injection.

Although the plasma CORT concentration of sparrows injected with Ringer's solution did not change significantly over the sampling period (One-way ANOVA, $F_{3,8}=1.19, p=0.37$, Fig. 1 ), plasma CORT in DEX-injected sparrows was significantly lower at 30,60 and 90 min post-injection $\left(F_{3,8}=10.5, p=0.0038\right)$. However, because plasma CORT of DEX-injected sparrows was significantly 


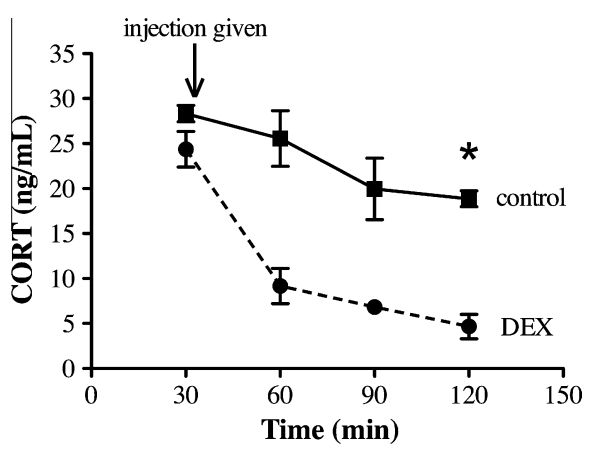

Fig. 1. Plasma corticosterone (CORT) response in house sparrows to intramuscular injection of either dexamethasone (DEX, $n=3$ ) or lactated Ringer's solution (control, $n=3$ ) following $30 \mathrm{~min}$ of restraint (indicated by arrow). Values are presented as means \pm SEM. ${ }^{*}=p<0.01$ compared to DEX at the same time point.

lower than that of control birds only at 90 min post-injection (Oneway ANOVA, $F_{1,4}=25.5, p=0.0072$ ), we waited $90 \mathrm{~min}$ before taking a post-DEX sample for all subsequent HPA function tests.

\subsection{HPA function tests}

Upon capture, birds were immediately removed from the net or trap and a baseline blood sample of $\sim 40$ ul taken within 3 min. Samples taken within this time frame are near baseline and easily distinguishable from stress-induced CORT concentrations in house sparrows [46]. Birds were then restrained in cloth bags for $30 \mathrm{~min}$, after which $\sim 25$ ul of blood was taken. To test negative feedback, we gave an intramuscular injection of DEX ( $1 \mathrm{mg} / \mathrm{kg}$ body weight) into the pectoral muscle and put birds back into cloth bags. After $90 \mathrm{~min}$, birds were removed from bags and a blood sample of $\sim 40$ ul was taken. We then gave animals an intramuscular injection of porcine adrenocorticotropic hormone (ACTH; $100 \mathrm{IU} / \mathrm{kg}$ body weight, Sigma Aldrich, St. Louis, MO). Because CORT secretion from the adrenal gland is primarily regulated by ACTH, an injection of exogenous ACTH can indicate adrenal sensitivity to an endogenous ACTH signal. This dose has been shown to be effective in eliciting a maximal response of CORT from the adrenals in house sparrows [39,43]. After an additional $15 \mathrm{~min}$ of restraint, a final blood sample of $\sim 25$ ul was taken and birds were put into a carrier for transport back to the lab. This procedure was repeated after 5 days of captivity, with baseline samples collected within 3 min of entering the animal room.

\subsection{Radioimmunoassays}

We determined CORT concentrations in each sample using radioimmunoassay (RIA) following the methods of Wingfield et al. [65]. Briefly, samples were allowed to equilibrate overnight with a small amount of radiolabeled CORT to determine individual recoveries. Each sample was extracted with redistilled dichloromethane, dried under nitrogen gas and re-suspended in phosphate-buffered saline with $1 \%$ gelatin. Samples were assayed in duplicate using antibody B3-163 (Esoterix, Calabasas Hills, CA) and CORT concentrations determined by comparison with a standard curve. Assay values were corrected for individual recoveries following extraction. Average recovery was 87\%; detectability was $1 \mathrm{ng}$ CORT/ml plasma. Intra- and inter-assay coefficients of variation were $3 \%$ and $22 \%$, respectively.

\subsection{Statistical analyses}

There are several possible ways to quantify an animal's ability to down-regulate its HPA axis using negative feedback. CORT titers of DEX-injected animals can be directly compared to non-injected animals over the same time period [49] and negative feedback can be measured as the decrease in CORT concentration/min following DEX injection [18]. In an attempt to isolate negative feedback from changes in stress-induced CORT (i.e. compensate for different stress-induced CORT titers used as the starting point for calculating negative feedback), we measured negative feedback as the relative decrease in CORT from stress-induced concentrations: (stress-induced CORT - post-DEX CORT)/(stress-induced CORT) $* 100$. Thus $100 \%$ feedback would represent the complete inhibition of CORT from the presumed peak of CORT release after $30 \mathrm{~min}$ of restraint.

During the first data collection period (early winter 2010), we were unable to obtain pre-captivity baseline CORT samples in under $3 \mathrm{~min}$. Because of this, we caught birds again in December 2011 to obtain baselines. This also provided an opportunity to determine if there were any year-to-year differences in other HPA values during the same season. However, as there were no significant year effects on mid-December values for stressinduced CORT, negative feedback or adrenal sensitivity (data not presented), early winter values from 2010 and 2011 were combined in these analyses.

Because we expected each HPA variable (baseline CORT, stressinduced CORT, negative feedback, and adrenal sensitivity) to be regulated independently $[24,27,37,43]$, we ran each one in a separate analysis. When examining initial differences among the six life history stages, as well as variables related to reproductive status, we used analysis of variance (ANOVA) in JMP 8.0 (SAS Institute Inc. 2009). ANOVA is fairly robust to violations of normality assumptions, but not to violations of homogeneity of variances [14], so in all cases we ensured that data met the homogeneity of variances assumption using Levene's test. In situations where variances among groups were not homogeneous, we ran a Welch's ANOVA [14]. When we found significant differences among groups in the ANOVA, we ran Tukey's HSD test as a multiple comparison procedure, as recommended by Quinn and Keough [36]. To assess the interaction of captivity effects and life history stage on the HPA axis, we used multivariate analysis of variance (MANOVA) in JMP 8.0 using pre- and post-captivity values as a repeated measure. To assess differences between pre- and post-captivity measures in each season, we used matched pairs analysis in JMP 8.0, and corrected for multiple comparisons using the sequential Bonferroni procedure [38]. Values are presented as means \pm SEM.

\section{Results}

\subsection{Reproductive status}

Male beak color varied by capture date $\left(F_{5,25}=37.5, p<0.0001\right.$, Fig. 2a). Beak color began to darken in early winter, had completely darkened by late winter, and stayed black until molt. Testes size also varied by capture date $\left(F_{5,21}=33.2, p<0.0001\right.$, Fig. $\left.2 b\right)$, but showed a different pattern from beak color. Testes size did not significantly increase until after the winter solstice, between the late winter and pre-laying periods, and remained large through the late breeding period. By molt, testes had regressed.

None of the females caught during the pre-laying period had fully defeathered brood patches, whereas all females caught during the breeding and late breeding periods had fully-developed defeathered brood patches with darkened skin (data not shown). Ovary mass varied significantly by capture date $\left(F_{5,19}=1.96\right.$, $p<0.0001$, Fig 2c). Ovary mass was significantly greater in the pre-laying period compared to early winter, and also in the breeding period compared to pre-laying. By the late breeding period, ovary mass had begun to decline, and during molt, ovaries had fully regressed. 

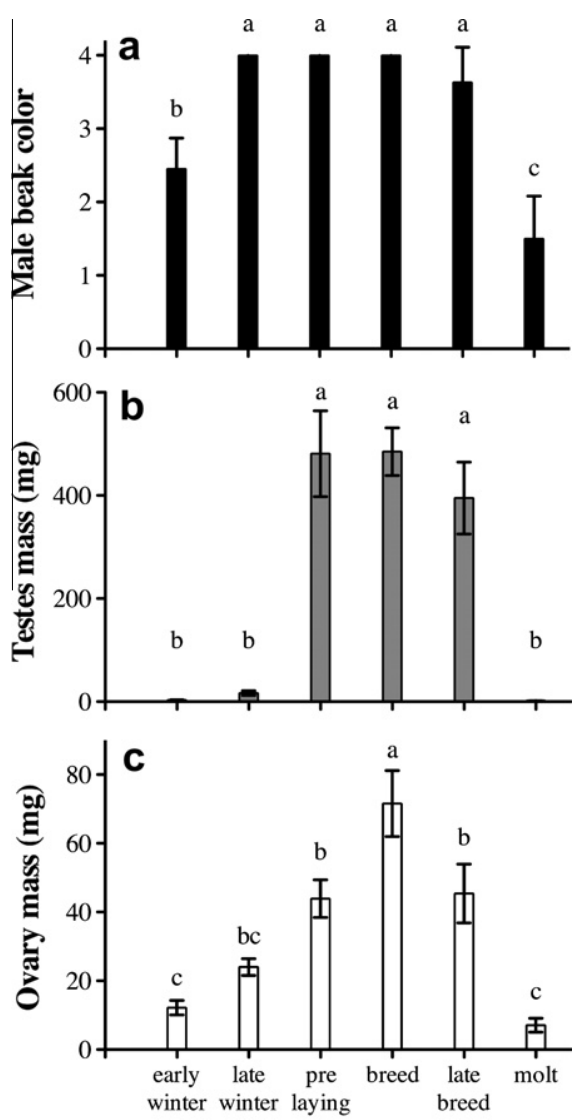

Life history stage

Fig. 2. (a) Beak color of male house sparrows ( $n=10$ at each life history stage, except for early winter, where $n=17$ ) scored using an arbitrary index of $1-4,1$ indicating uniform light yellow or horn color and 4 indicating uniform jet black. b. Testes mass of male house sparrows ( $n=10$ at each life history stage, except for early winter, where $n=17$ ). c. Ovary mass of female house sparrows ( $n=10$ at each life history stage, except for early winter, where $n=13$ ). Different letters represent statistical differences as indicated by post hoc tests. Values are presented as means \pm SEM.

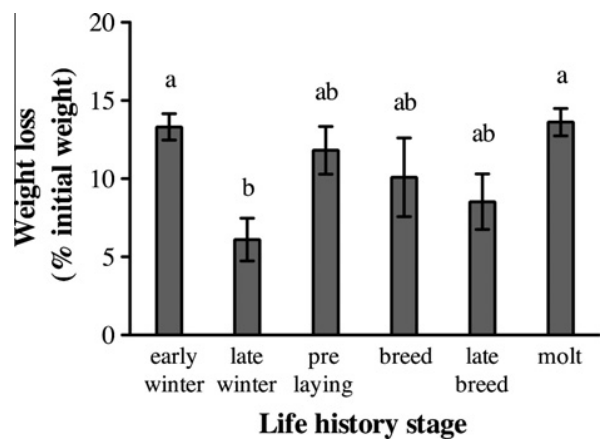

Fig. 3. Weight loss of house sparrows (expressed as percent of initial weight) after 5 days of captivity at six different life history stages: early winter (Dec, $n=17$ ), late winter (Feb, $n=8$ ), pre-laying (Apr, $n=8$ ), breeding (May, $n=8$ ), late breeding (July, $n=8$ ), and molt (Sept, $n=9$ ). Different letters represent statistical differences as indicated by post hoc tests. All values are presented as means \pm SEM.

\subsection{Weight loss}

Pre-captivity body mass did not differ seasonally $\left(F_{5,53}=1.96\right.$, $p=0.10)$. House sparrows $(n=58)$ lost a significant amount of body mass after 5 days of captivity $\left(F_{1,52}=263.9, p<0.0001\right)$, resulting in a mean weight loss of $11.0 \pm 0.7 \%$. However, the percent weight loss during captivity varied by life history stage $\left(F_{5,52}=4.16, p=\right.$

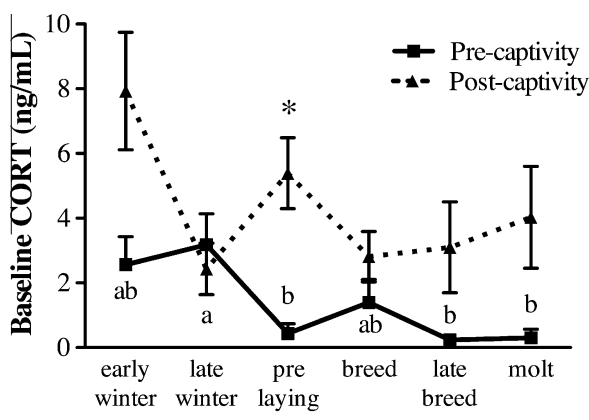

Life history stage

Fig. 4. Pre- and post-captivity baseline plasma corticosterone (CORT) of house sparrows at six different life history stages. See Fig. 3 caption for sample sizes. Different letters represent statistical differences among pre-captivity groups as indicated by post hoc tests; stars represent statistical differences between pre- vs. post-captivity samples using matched-pairs analysis with sequential Bonferroni corrections. See text for statistical analyses on overall effects of captivity. All values are presented as means \pm SEM.

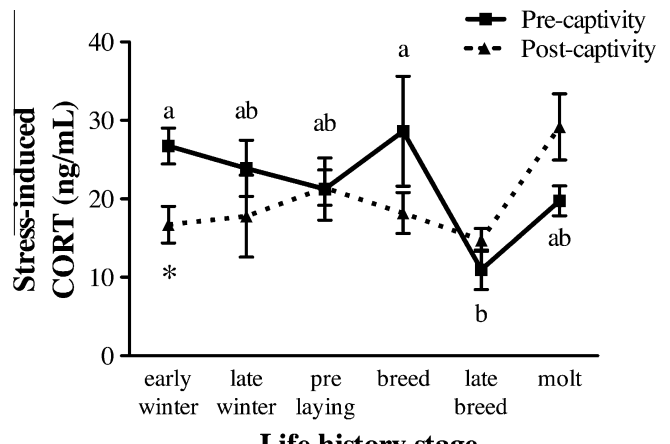

Life history stage

Fig. 5. Pre- and post-captivity stress-induced plasma corticosterone (CORT) of house sparrows at six different life history stages. See Fig. 3 caption for sample sizes. Different letters represent statistical differences among pre-captivity groups as indicated by post hoc tests; stars represent statistical differences between prevs. post-captivity samples using matched-pairs analysis with sequential Bonferroni corrections. See text for statistical analyses on overall effects of captivity. All values are presented as means \pm SEM.

0.0030, Fig. 3). Post-hoc analysis revealed that birds lost less weight in captivity in late winter compared to molt and early winter.

\subsection{Baseline CORT}

Pre-captivity baseline CORT varied by life history stage $\left(F_{5,19}=3.17, p=0.030\right.$, Fig. 4$)$, and post hoc analysis revealed that baseline CORT was higher in late winter than during pre-laying, late breeding, or molt. Baseline CORT increased after five days of captivity $\left(F_{1,42}=22.9, p<0.0001\right)$, regardless of life history stage (interaction captivity $*$ month, $F_{5,42}=2.3, p=0.060$ ). Despite this overall significant effect, matched-pairs analysis only showed a significant increase in baseline CORT in the pre-laying period $(p=0.0021)$.

\subsection{Stress-induced CORT}

Pre-captivity stress-induced CORT varied depending on life history stage $\left(F_{5,21}=4.3, p=0.0075\right.$, Fig. 5$)$. Post-hoc analysis indicated that stress-induced CORT was higher during breeding and early winter than during late breeding. There was no overall effect of captivity on stress-induced CORT $\left(F_{1,52}=1.1, p=0.29\right)$, although there was a significant interaction between captivity and life 


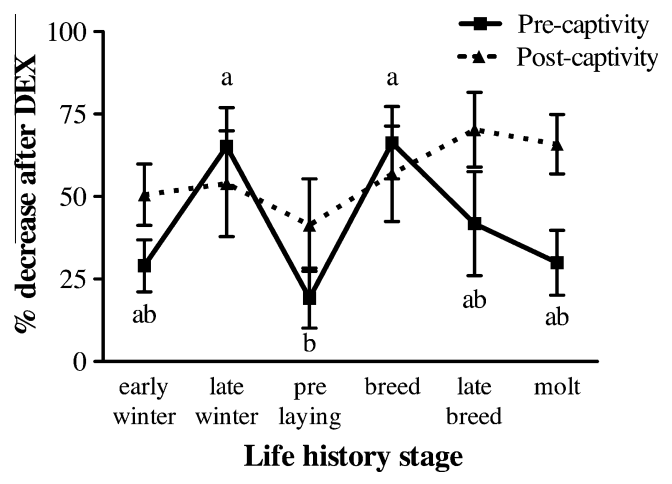

Fig. 6. Percent decrease from stress-induced plasma corticosterone (CORT) in house sparrows $90 \mathrm{~min}$ after a $1 \mathrm{mg} / \mathrm{kg}$ body weight injection of dexamethasone (DEX) at six different life history stages. See Fig. 3 caption for sample sizes. Note that $100 \%$ negative feedback represents complete shutting off of CORT release, whereas 0\% represents complete resistance to DEX-induced feedback. Different letters represent statistical differences among pre-captivity groups as indicated by post hoc tests; stars represent statistical differences between pre- vs. post-captivity samples using matched-pairs analysis with sequential Bonferroni corrections. See text for statistical analyses on overall effects of captivity. All values are presented as means \pm SEM.

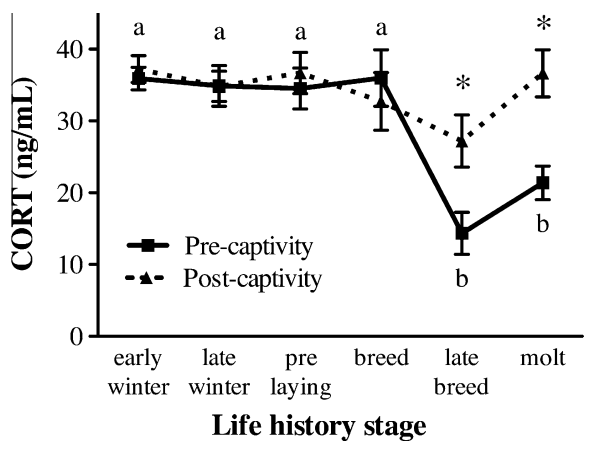

Fig. 7. Plasma corticosterone (CORT) concentrations of house sparrows $15 \mathrm{~min}$ after a $100 \mathrm{IU} / \mathrm{kg}$ body weight injection of adrenocorticotropic hormone (ACTH) at six different life history stages. See Fig. 3 caption for sample sizes. Different letters represent statistical differences among pre-captivity groups as indicated by post hoc tests; stars represent statistical differences between pre- vs. post-captivity samples using matched-pairs analysis with sequential Bonferroni corrections. See text for statistical analyses on overall effects of captivity. All values are presented as means \pm SEM.

history stage $\left(F_{5,52}=2.8, \quad p=0.025\right)$. Matched-pairs analysis showed a significant decrease in stress-induced CORT in early winter $(p=0.0082)$.

\subsection{Negative feedback}

Pre-captivity negative feedback varied by life history stage $\left(F_{5,52}=3.1, p=0.017\right.$, Fig. 6$)$. Note that $100 \%$ negative feedback represents a complete shut off of CORT release, whereas $0 \%$ represents complete resistance to DEX-induced feedback. Post-hoc analysis revealed that negative feedback efficacy was reduced during prelaying compared to breeding and late winter. Overall, negative feedback efficacy increased after five days of captivity $\left(F_{1,52}=5.2\right.$, $p=0.026$ ), regardless of life history stage (interaction captivity $*$ month, $F_{5,52}=1.5, p=0.20$ ). Despite this overall significant effect, matched-pairs analysis did not show a significant increase in negative feedback at any one life history stage.

\subsection{Adrenal sensitivity}

Pre-captivity adrenal sensitivity varied according to life history stage $\left(F_{5,53}=12.1, p<0.0001\right.$, Fig. 7$)$. Post-hoc analysis revealed that sparrows showed reduced adrenal sensitivity during molt and the late breeding period. Overall, there was a significant effect of captivity on adrenal sensitivity $\left(F_{1,52}=10.6, p=0.0020\right)$ and a significant interaction between captivity and life history stage $\left(F_{5,52}=4.3, p=0.0024\right)$. Matched pairs analysis showed increases in adrenal sensitivity during captivity during late breeding $(p=0.0018)$ and molt $(p=0.0076)$.

\section{Discussion}

\subsection{Reproductive status}

Beak color in males is an androgen-dependent secondary-sex characteristic that can also indicate reproductive status [25,28] In house sparrows breeding in New England, gonadal development is initiated after fall molt, but the gonads typically remain very small until a period of rapid growth in late winter after the solstice $[2,22]$. However, beak color in males begins to darken in the late fall/early winter, indicating increasing testosterone concentrations and the initiation of testicular recrudescence [22]. Consistent with previous work, we found that male beak color had completely darkened by late winter, indicating an increase in circulating testosterone at this time. However, testes size did not increase significantly until the transition from late winter to pre-laying, a period of a little over one month.

In female house sparrows, the brood patch begins to develop during nest-building and egg-laying of the first brood, but complete defeathering and vascularization of the patch does not occur until the end of the laying period $[2,55]$. None of the females we caught during the pre-laying period had fully defeathered brood patches, indicating that they had not yet laid their first clutches. By contrast, all females caught during the breeding and late breeding periods had fully developed defeathered brood patches with darkened skin, indicating that they had laid at least one clutch, and they had not yet begun to re-grow brood patch feathers [55].

Ovary mass also showed that females caught in late Marchearly April were, indeed, pre-laying; mean ovary mass was $44 \mathrm{mg}$ (range: $23-74 \mathrm{mg}$ ), compared to over $200 \mathrm{mg}$ for a laying female house sparrow [41]. By contrast, although ovary mass was significantly greater when sparrows were caught in the breeding period compared to the pre-laying period, "breeding" individuals could not be definitively assigned to breeding sub-stage. However, as mentioned previously, we were most interested in understanding how HPA function might change before vs. after egg-laying, rather than within specific nesting sub-stages, which has already been examined in house sparrows in New England [23]. Plasma CORT concentrations are relatively independent of breeding sub-stage in late-season broods [23]. By mid-late July, ovary mass had begun to decline, suggesting late breeding females were raising their final brood, and CORT should not be affected by differences in breeding sub-stage.

\subsection{Seasonal changes in the HPA axis}

Data presented here indicate that HPA axis activity in house sparrows varies throughout the year. These data are consistent with similar studies using a more limited number of life-history stages $[43,44]$. In addition, this study is the first to assess seasonal variation in negative feedback in a wild species. Because negative feedback has emerged in several recent studies as an essential factor determining whether animals can adaptively respond to stressors $[17,49]$, knowing that negative feedback is also regulated seasonally can be valuable for interpreting future studies.

Overall, the trends we see in the HPA axis by life history stage in house sparrows are consistent with changing physiological and 
behavioral needs, as well as trade-offs associated with molt. For example, house sparrows in late winter have elevated baseline CORT and increased negative feedback compared with several other life history stages. This increase in baseline CORT might indicate increased metabolic demands associated with the need to regrow gonads for spring breeding ([10,59]; but see also [9]). If this were the case, elevated baseline CORT at this time of year may be consistent with the Energy Mobilization Hypothesis, which predicts that plasma CORT concentrations will be high during energetically costly periods $[13,42]$.

Birds captured just a few weeks later, in the pre-laying period, showed very different HPA function, with decreased baseline CORT and negative feedback compared to late winter birds. At this point, male testes had fully recrudesced, but female gonads were still growing. This decrease in negative feedback may be consistent with the Behavioral Hypothesis [63], which posits that annual changes in CORT concentrations might result from animals having different requirements for expressing CORT-mediated behaviors at different times of year. Varying CORT concentrations might act as one mechanism by which supplementary cues such as food availability and weather could help fine-tune the onset of breeding $[8,54,60]$. For example, in white-crowned sparrows (Zonotrichia leucophrys), CORT has been implicated in temporary abandonment of breeding territories during inclement weather [6]. If the HPA axis of house sparrows in the pre-laying period is more sensitive to prolonged stress-induced CORT, as would be the case with decreased efficacy of negative feedback, this may help sparrows better time egg-laying in response to severe weather, food shortages, and other stressors that can be associated with early spring in New England.

When sparrows were in breeding condition, they up-regulated both stress-induced CORT and the efficacy of negative feedback. This means that these sparrows were able to respond robustly to stressors in their environment, but were also able to quickly bring stress-induced concentrations back to baseline. Again, the change in negative feedback makes sense when viewed from the perspective of the Behavioral Hypothesis - at this point in the year, all sparrows had laid at least one clutch of eggs, and it would have been disadvantageous to abandon nesting attempts in response to transitory stressors [62]. The increase in stress-induced CORT may be consistent with the Preparative Hypothesis [42], which states that annual changes in CORT concentrations may be related to predictable changes in the likelihood of encountering stressors at different life history stages. House sparrows are normally found in large flocks, but during breeding, they are more likely to be solitary or in pairs [2]. This change in sociality may be associated with increased predation risk $[21,57]$. More research is needed to explore this hypothesis, and to determine whether there are other predictable increases in stressors associated with breeding. One potential weakness of the present study was that we did not determine breeding sub-stage, which has been shown to affect plasma CORT concentrations during early broods in house sparrows [23]. The sampling of breeding birds at different breeding sub-stages could obscure patterns that might otherwise exist in the data.

Late breeding and molt were associated with decreased baseline and stress-induced CORT, attenuated negative feedback, and attenuated adrenal sensitivity - a "turning down" of the entire HPA axis. In fact, a down-regulation of baseline and stress-induced CORT during molt is the most consistent and robust seasonal change in HPA function in birds (Romero 2002). Because feathers are made of protein, and one of CORT's actions is to break down protein (see Landys et al. [27] for a review of CORT's catabolic effects), this down-regulation of the stress response may be necessary for birds to grow high-quality feathers. Exogenous CORT applied to molting birds resulted in slower-growing feathers [48] and feathers of lower quality [15]. Thus, during molt, birds seem to trade off the ability to respond to environmental challenges for the ability to grow a set of high-quality feathers, necessary for flight and thermoregulation [35,58].

Although we initially chose to look at sparrows in mid-late July because we were interested in the stress physiology of late breeders, it may be more accurate to think of sparrows during this time of year as "pre-molting." Certainly, the pattern of HPA function in these birds was closer to the pattern in molting birds than in breeding birds. Avian molt involves significant increases in the rates of oxygen consumption [52] and whole-body protein synthesis [34], and it is not clear exactly when birds must adjust physiologically to prepare for molt. Recent work indicated that CORT release and the fight-or-flight response showed a pattern consistent with molt two weeks prior to the onset of feather loss in European starlings, and the transition may have taken place far earlier [26].

\subsection{Chronic stress effects on the HPA axis at different life history stages}

Consistent with previous studies in other animal models [4,18, 29,64], the initial transference to captivity affected the HPA function of house sparrows in ways consistent with a persistent strong, or chronic, stressor (Table 1). Some captivity effects (weight loss, increases in baseline CORT and stronger negative feedback) were fairly consistent regardless of life history stage. Other captivity effects (such as decreased stress-induced CORT in early winter) varied by life history stage. This adds to a growing body of literature showing that chronic stress can have major effects on the HPA function of wild animals [11,12,17,19,29,40,50].

However, the specific HPA components affected by chronic stress, such as baseline versus stress-induced CORT, and the direction of those effects, are not always consistent from study to study. For example, in a study that applied randomized 30-min stressors to a population of wild European starlings (Sturnus vulgaris) for 8 days, Cyr et al. [12] found that baseline CORT decreased, rather than increased as in this study. Similarly, Dickens et al. [18] saw decreased baseline CORT and negative feedback 5 days after the initial transference to captivity in breeding chukar (Alectoris chukar), an opposite pattern from the one we observed in breeding house sparrows. The type and direction of effects on HPA function may depend in part on whether the chronic stressor is sustained, such as in the case of bringing wild animals into captivity, or random and intermittent, as in the case of Cyr et al. [12]. It could also depend on the duration of the stressor $[17,30]$, or the species affected $[3,31]$. In any case, this study makes clear that a further factor that could affect chronic stress-induced changes in HPA function is the life history stage of the impacted animals.

There were three broad patterns of response to captivity in House Sparrows that occurred across nearly all life history stages. These were: a decrease in body mass, an increase in baseline CORT,

\section{Table 1}

Summary of differences in response to 5 days of captivity by life history stage in house sparrows caught in Massachusetts. "Overall effect" arrows represent significant increases or decreases due to captivity across all life history stages as determined using repeated-measures MANOVA. "Specific effect by life history stage" arrows represent significant increases or decreases due to captivity in particular life history stages as determined using ANOVA with Tukey's post hoc tests (for body mass) or matched-pairs analysis with sequential Bonferroni corrections (for all other variables).

\begin{tabular}{|c|c|c|}
\hline Variable & $\begin{array}{l}\text { Overall } \\
\text { effect }\end{array}$ & Specific effect by life history stage \\
\hline Body mass & $\downarrow$ & $\begin{array}{l}\text { Greatest loss in molt and early winter } \\
\text { compared to late winter }\end{array}$ \\
\hline Baseline CORT & $\uparrow$ & $\uparrow$ in pre-laying \\
\hline Stress-induced CORT & - & $\downarrow$ in early winter \\
\hline Negative feedback & $\uparrow$ & - \\
\hline Adrenal sensitivity & $\uparrow$ & $\uparrow$ in late breeding and molt \\
\hline
\end{tabular}


and an increase in negative feedback. This increase in baseline CORT might have been due to captivity-induced increases in activity, requiring extra energy mobilization, and could have been partly responsible for the decrease in body mass [27,51]. Increased negative feedback might reflect sparrows' initial attempts to cope with chronic stress by reducing the duration of the physiological response to acute stressors such as humans entering the room for animal husbandry.

Late-breeding and molting sparrows had very different responses to the chronic stress of captivity than birds during the rest of the year. During both of these life history stages, birds up-regulated adrenal sensitivity after 5 days of captivity; during molt, they also lost more body mass. As discussed earlier, the need to produce high-quality feathers seemed to trump the importance of being able to respond to environmental stressors in free-living birds; however, the chronic stress resulting from the transfer of wild birds to captivity interfered with that process. There was upregulation of adrenal sensitivity as a result of chronic stress in these birds, which could cause increased sensitivity to stress-related pathologies [33]. Furthermore, in birds that are already molting, chronic stress may cause birds to grow lower-quality feathers [15]. In fact, the simultaneous demands of molting and chronic stress resulting from captivity may be part of the reason that molting birds lost significantly more weight than sparrows at other times of year.

In conclusion, HPA function in wild House Sparrows varied among different life history stages in ways that had subsequent impacts on their physiological response to the chronic stress of captivity. Because of this, it may be desirable to avoid bringing birds into captivity during particularly vulnerable stages (such as during molt in birds) for purposes such as translocation.

\section{Acknowledgments}

Special thanks to M. McVey and S. Lefebvre for providing field sites, to K. Waldron-Francis, C. Medina, J. Cash, D. Merullo, L. Wang, C. Hui, C. Le, S. Durant and C. Parker for assistance catching and sampling wild house sparrows, to J. M. Reed for help with statistical analyses and D. Keniston for help scoring beak color. Funding was provided by the EPA STAR Fellowship program and a Tufts University Graduate Student Research Award to CRL and National Science Foundation (USA) grant IOS-1048529 to LMR. We thank two anonymous reviewers for useful comments on the manuscript.

\section{References}

[1] Z. Amirat, F. Khammar, R. Brudieux, Seasonal changes in plasma and adrenal concentrations of cortisol, corticosterone, aldosterone, and electrolytes in the adult male sand rat (Psammomys obesus), Gen. Comp. Endocr. 40 (1980) 36-43.

[2] T.R. Anderson, Biology of the Ubiquitous House Sparrow: From Genes to Populations, Oxford University Press, 2006.

[3] F. Angelier, B. Ballentine, R.L. Holberton, P.P. Marra, R. Greenberg, What drives variation in the corticosterone stress response between subspecies? A common garden experiment of swamp sparrows (Melospiza georgiana), J. Evol. Biol. 24 (2011) 1274-1283.

[4] M.L. Baker, E. Gemmell, R.T. Gemmell, Physiological changes in brushtail possums, Trichosurus vulpecula, transferred from the wild to captivity, J. Exp. Zool. 280 (1998) 203-212.

[5] S.L. Berga, Stress and reproduction: a tale of false dichotomy?, Endocrinology 149 (2008) 867-868

[6] C.W. Breuner, T.P. Hahn, Integrating stress physiology, environmental change and behavior in free-living sparrows, Horm. Behav. 43 (2003) 115-123.

[7] C.W. Breuner, J.C. Wingfield, L.M. Romero, Diel rhythms of basal and stressinduced corticosterone in a wild, seasonal vertebrate Gambel's white-crowned sparrow, J. Exp. Zool. 284 (1999) 334-342.

[8] J.R. Cain, R.J. Lien, A model for drought inhibition of bobwhite quail (Colinus virginianus) reproductive systems, Comp. Biochem. Physiol. Part A: Mol. Integr. Physiol. 82 (1985) 925-930.

[9] S.P. Caro, M.E. Visser, Temperature-induced elevation of basal metabolic rate does not affect testis growth in great tits, J. Exp. Biol. 212 (2009) 1995-1999.
[10] M.A. Chappell, C. Bech, W.A. Buttemer, The relationship of central and peripheral organ masses to aerobic performance variation in house sparrows, J. Exp. Biol. 202 (1999) 2269-2279.

[11] N.E. Cyr, K. Earle, C. Tam, L.M. Romero, The effect of chronic psychological stress on corticosterone, plasma metabolites, and immune responsiveness in European starlings, Gen. Comp. Endocr. 154 (2007) 59-66.

[12] N.E. Cyr, L.M. Romero, Chronic stress in free-living European starlings reduces corticosterone concentrations and reproductive success, Gen. Comp. Endocr. 151 (2007) 82-89.

[13] M.F. Dallman, A.M. Strack, S.F. Akana, M.J. Bradbury, E.S. Hanson, K.A. Scribner et al., Feast and famine: critical role of glucocorticoids with insulin in daily energy flow, Front Neuroendocrin. 14 (1993) 303-347.

[14] R.W. Day, G.P. Quinn, Comparisons of treatments after an analysis of variance in ecology, Ecol. Monogr. 59 (1989) 433-463.

[15] D.W. DesRochers, J.M. Reed, J. Awerman, J.A. Kluge, J. Wilkinson, L.I. van Griethuijsen, et al., Exogenous and endogenous corticosterone alter feather quality, Comp. Biochem. Phys. A 152 (2009) 46-52.

[16] F.S. Dhabhar, B.S. McEwen, Acute stress enhances while chronic stress suppresses cell-mediated immunity in vivo: a potential role for leukocyte trafficking, Brain. Behav. Immun. 11 (1997) 286-306.

[17] M.J. Dickens, D.J. Delehanty, L.M. Romero, Stress and translocation: alterations in the stress physiology of translocated birds, Proc. R. Soc. Lond. Ser. B Biol. Sci. 276 (2009) 2051-2056.

[18] M.J. Dickens, K.A. Earle, L.M. Romero, Initial transference of wild birds to captivity alters stress physiology, Gen. Comp. Endocr. 160 (2009) 76-83.

[19] M.J. Dickens, L.M. Romero, N. Cyr, I.C. Dunn, S.L. Meddle, Chronic stress alters glucocorticoid receptor and mineralocorticoid receptor mRNA expression in the European Starling (Sturnus vulgaris) brain, J. Neuroendocrinol. 21 (2009) $832-840$.

[20] H.B. Fokidis, P. Deviche, Plasma corticosterone of city and desert Curve-billed Thrashers, Toxostoma curvirostre, in response to stress-related peptide administration, Comp. Biochem. Physiol. A Mol. Integr. Physiol. 159 (2011) 32-38.

[21] F. Gotmark, P. Post, Prey selection by sparrowhawks, Accipter nisus: relative predation risk for breeding passerine birds in relation to their size, ecology and behavior, Philos. T. R. Soc. B. 351 (1996) 1559-1577.

[22] R.E. Hegner, J.C. Wingfield, Gonadal development during autumn and winter in house sparrows, Condor 88 (1986) 269-278.

[23] R.E. Hegner, J.C. Wingfield, Annual cycle of gonad size, reproductive hormones and breeding activity of free-living house sparrows (Passer domesticus (L.)) in rural New York, in: J. Pinowski, J.D. Summers-Smith (Eds.), Granivorous Birds in the Agricultural Landscape, Polish Scientific Publishers, Warsaw, 1990, pp. $123-135$.

[24] Z.G. Hodgson, S.L. Meddle, M.L. Roberts, K.L. Buchanan, M.R. Evans, R. Metzdorf, et al., Spatial ability is impaired and hippocampal mineralocorticoid receptor mRNA expression reduced in zebra finches (Taeniopygia guttata) selected for acute high corticosterone response to stress, Proc. R. Soc. B. 274 (2007) 239-245.

[25] A. Kirschbaum, C.A. Pfeiffer, Deposition of melanin in sparrow bill following local action of testosterone propionate in alchoholic solution, Proce. Soc. Exp. Biol. Med. 46 (1941) 649-651.

[26] S. Kostelanetz, M.J. Dickens, L.M. Romero, Combined effects of molt and chronic stress on heart rate, heart rate variability, and glucocorticoid physiology in European Starlings, Comp. Biochem. Phys. Part A: Mol. Integr. Phys. 154 (2009) 493-501.

[27] M.M. Landys, M. Ramenofsky, J.C. Wingfield, Actions of glucocorticoids at a seasonal baseline as compared to stress-related levels in the regulation of periodic life processes, Gen. Comp. Endocr. 148 (2006) 132-149.

[28] S. Laucht, B. Kempenaers, J. Dale, Bill color, not badge size, indicates testosterone-related information in house sparrows, Behav. Ecol. Sociobiol. 64 (2010) 1461-1471.

[29] P.P. Marra, K.T. Lampe, B.L. Tedford, Plasma corticosterone levels in two species of Zonotrichia sparrows under captive and free-living conditions, Wilson Bull. 107 (1995) 296-305.

[30] O. Marti, J. Marti, A. Armario, Effects of chronic stress on food intake in rats influence of stressor intensity and duration of daily exposure, Physiol. Behav. 55 (1994) 747-753.

[31] G.J. Mason, Species differences in responses to captivity: stress, welfare and the comparative method, Trends Ecol. Evol. 25 (2010) 713-721.

[32] B.S. McEwen, J.C. Wingfield, The concept of allostasis in biology and biomedicine hormones and behavior. 43 (2003) 2-15.

[33] A.U. Munck, P.M. Guyre, N. Holbrook, Physiological actions of glucocorticoids in stress and their relation to pharmacological actions, Endocr. Rev. 5 (1984) 25-41.

[34] M.E. Murphy, T.G. Taruscio, Sparrows increase their rates of tissue and wholebody protein synthesis during the annual molt, Comp. Biochem. Phys. Part A: Mol. Integr. Phys. 111 (1995) 385-396.

[35] J.-A. Nilsson, E. Svensson, The cost of reproduction: a new link between current reproductive effort and future reproductive success, Proc. R. Soc. B 263 (1996) 711-714.

[36] G.P. Quinn, M.J. Keough, Comparing groups or treatments - analysis of variance, in: Experimental Design and Data Analysis for Biologists, Cambridge University Press, New York, 2002, pp. 173-207.

[37] J.M.H.M. Reul, F.R. van den Bosch, E.R. De Kloet, Relative occupation of type-I and type-II corticosteroid receptors in rat brain following stress and 
dexamethasone treatment: functional implications, J. Endocr. 115 (1987) 459467.

[38] W.R. Rice, Analyzing tables of statistical tests, Evolution 43 (1989) 223-225.

[39] E.L. Rich, L.M. Romero, Daily and photoperiod variations of basal and stressinduced corticosterone concentrations in house sparrows (Passer domesticus), J. Comp. Physiol. B 171 (2001) 543-547.

[40] E.L. Rich, L.M. Romero, Exposure to chronic stress downregulates corticosterone responses to acute stressors, Am. J. Phys. Regul. Integr. Comp. Phys. 288 (2005) R1628-R1636.

[41] G.M. Riley, E. Witschi, Comparative effects of light stimulation and administration of gonadotropic hormones on female sparrows, Endocrinology 23 (1938) 618-624.

[42] L.M. Romero, Seasonal changes in plasma glucocorticoid concentrations in free-living vertebrates, Gen. Comput. Endocr. 128 (2002) 1-24.

[43] L.M. Romero, Seasonal changes in hypothalamic-pituitary-adrenal axis sensitivity in free-living house sparrows (Passer domesticus), Gen. Comp. Endocr. 149 (2006) 66-71.

[44] L.M. Romero, N.E. Cyr, R.C. Romero, Corticosterone responses change seasonally in free-living house sparrows (Passer domesticus), Gen. Comp. Endocr. 149 (2006) 58-65.

[45] L.M. Romero, M.J. Dickens, N.E. Cyr, The reactive scope model - a new model integrating homeostasis, allostasis, and stress, Horm. Behav. 55 (2009) 375389.

[46] L.M. Romero, J.M. Reed, Collecting baseline corticosterone samples in the field: is under 3 min good enough?, Comp Biochem. Phys. Part A 140 (2005) 73-79.

[47] L.M. Romero, L. Remage-Healey, Daily and seasonal variation in response to stress in captive starlings (Sturnus vulgaris): corticosterone, Gen. Comp. Endocr. 119 (2000) 52-59.

[48] L.M. Romero, D.E. Strochlic, J.C. Wingfield, Corticosterone inhibits feather growth: potential mechanism explaining seasonal down regulation of corticosterone during molt, Comp. Biochem. Phys. Part A: Mol. Integrative Phys. 142 (2005) 65-73.

[49] L.M. Romero, M. Wikelski, Stress physiology as a predictor of survival in Galapagos marine iguanas, Proc. R. Soc. B 277 (2010) 3157-3162.

[50] R.M. Sapolsky, Hypercortisolism among socially subordinate wild baboons originates at the CNS level, Arch. Gen. Psychiat. 46 (1989) 1047-1051.

[51] R.M. Sapolsky, L.M. Romero, A.U. Munck, How do glucocorticoids influence stress responses? Integrating permissive, suppressive, stimulatory, and preparative actions, Endocr. Rev. 21 (2000) 55-89.
[52] P.C. Schieltz, M.E. Murphy, Diurnal variation in oxygen consumption by molting and nonmolting sparrows, Comp. Biochem. Phys. Part A: Mol. Integr. Phys. 112 (1995) 265-272.

[53] K.L. Schmidt, A.A. Furlonger, J.M. Lapierre, E.A. MacDougall-Shackleton, S.A. MacDougall-Shackleton, Regulation of the HPA axis is related to song complexity and measures of phenotypic quality in song sparrows, Horm. Behav. 61 (2012) 652-659.

[54] S.J. Schoech, Food supplementation experiments: a tool to reveal mechanisms that mediate timing of reproduction, Integr. Comput. Biol. 49 (2009) 480-492.

[55] R.K. Selander, S.Y. Yang, The incubation patch of the house sparrow, Passer domesticus Linnaeus, Gen. Comp. Endocr. 6 (1966) 325-333.

[56] D.H. Sheppard, Seasonal changes in body and adrenal weights of chipmunks (Eutamias), J. Mammol. 49 (1968) 463-474.

[57] M. Studd, R.D. Montgomerie, R.J. Robertson, Group size and predator surveillance in foraging house sparrows (Passer domesticus), Can. J. Zool. 61 (1983) 226-231.

[58] J.P. Swaddle, M.S. Witter, I.C. Cuthill, A. Budden, P. McCowen, Plumage condition affects flight performance in common starlings: implications for developmental homeostasis, abrasion and moult, J. Avian. Biol. 27 (1996) 103111.

[59] F. Vézina, K.G. Salvante, Behavioral and physiological flexibility are used by birds to manage energy and support investment in the early stages of reproduction, Current Zool. 56 (2010) 767-792.

[60] J.C. Wingfield, T.P. Hahn, R. Levin, P. Honey, Environmental predictability and control of gonadal cycles in birds, J. Exp. Zool. 261 (1992) 214-231.

[61] J.C. Wingfield, G.J. Kenagy, Natural regulation of reproductive cycles, in: P.K.T Pang, M.P. Schreibman (Eds.), Vertebrate Endocrinology: Fundamentals and Biomedical Implications, Academic Press, San Diego, CA, 1991, pp. 181-241.

[62] J.C. Wingfield, D.L. Maney, C.W. Breuner, J.D. Jacobs, S. Lynn, M. Ramenofsky, et al., Ecological bases of hormone-behavior interactions: the "emergency life history stage", Am. Zool. 38 (1998) 191-206.

[63] J.C. Wingfield, L.M. Romero, Adrenocortical responses to stress and their modulation in free-living vertebrates, in: B.S. McEwen, H.M. Goodman (Eds.), Handbook of Physiology; Section 7: The Endocrine System; Volume IV: Coping with the Environment: Neural and Endocrine Mechanisms, Oxford University Press, New York, 2001, pp. 211-234.

[64] J.C. Wingfield, J.P. Smith, D.S. Farner, Endocrine responses of white-crowned sparrows to environmental stress, Condor 84 (1992) 399-409.

[65] J.C. Wingfield, C.M. Vleck, M.C. Moore, Seasonal changes of the adrenocortical response to stress in birds of the Sonoran Desert, J. Exp. Zool. 264 (1992) 419-428. 